\title{
Studi Kasus Asuhan Keperawatan Psikososial Pada Ny. L Dengan Masalah Kecemasan Di Jalan Amal Luhur \\ Yolanda Wulandari \\ yolandawulandari27@gmail.com
}

\section{BAB 1}

\section{PENDAHULUAN}

\subsection{Latar Belakang}

Hipertensi merupakan penyakit kardiovaskuler atau kategori penyakit yang tidak menular (PTM) yang telah menjadi endemik. Hipertensi adalah suatu keadaan dimana tekanan darah sistolik $\geq 140 \mathrm{mmHg}$ dan atau tekanan darah diastolik $\geq 90 \mathrm{mmHg}$. Hipertensi sering disebut sebagai "the silent killer" (pembunuh siluman), karena sering kali penderita hipertensi bertahun-tahun tanpa merasakan sesuatu gangguan atau gejala. Tanpa disadari penderita mengalami komplikasi pada organ-organ vital seperti jantung, otak ataupun ginjal. Gejala-gejala akibat hipertensi, seperti pusing, gangguan penglihatan, dan sakit kepala, sering kali terjadi pada saat hipertensi sudah lanjut disaat tekanan darah sudah mencapai angka tertentu yang bermakna (Triyanto E, 2019).

Menurut World Health Organization (WHO) tahun 2016, satu milyar orang di dunia menderita hipertensi, dua pertiga diantaranya berada di Negara berkembang yang berpenghasilan rendah-sedang. Prevalensi hipertensi akan terus meningkat tajam, diprediksikan pada tahun 2025 nanti, sekitar 29\% orang dewasa di seluruh dunia menderita hipertensi. Hipertensi telah mengakibatkan kematian sekitar 8 juta orang setiap tahun, 1,5 juta kematian terjadi di Asia Tenggara, yang sepertiga populasinya menderita hipertensi (Kemenkes RI, 2013).

Di Indonesia prevalensi kecemasan belum diketahui secara pasti, namun diprdiksi sekitar 9-12\% populasi penduduk mengalami kecemasan. Hasil 
penelitian Apriansyah, Romadoni dan Andrianovita (2014) bahwa responden yang akan dilakukan tindakan operasi mengalami kecemasan kategori sedang dan berat berjumlah 23 responden (50\%) dari total 46 responden yang diteliti dan kecemasan ringan yang terjadi pada responden demngan keluhan nyeri berjumlah 10 responden $(21,7 \%)$ dari total 46 responden (Pardede et al., 2021)

Kota Medan Merupakan salah satu Kota Di Provinsi Sumatera Utara yang memiliki masalah dengan hipertensi. Berdasarkan data Indeks Pembangunan Kesehatan Masyarakat tahun 2016, prevalensi hipertensi Kota Medan adalah $26,27 \%$, data ini lebih tinggi dari prevalensi Sumatera Utara $(22,99 \%)$ dan prevalensi Indonesia (24,33\%). Kecamatan Medan Helvetia merupakan kecamatan dengan jumlah kasus tertinggi di kota Medan pada tahun 2017. Data kasus hipertensi pada dewasa muda di kecamatan medan Helvetia pada tahun 2014 adalah 544 orang dan jumlah penduduk usia 18-45 tahun adalah 108.626 orang.

Menurut data dari Riskesdas tahun 2017 menyatakan bahwa lansia yang mengalami kecemasan menyebabkan terjadinya peningkatan tekanan darah. Kecemasan adalah kekhawatiran yang tidak jelas dan menyebar yang berkaitan dengan perasaan tidak pasti dan tidak berdaya. Keadaan emosi ini tidak memiliki obyek yang spesifik. Gangguan kecemasan dan depresi di derita oleh 40 juta populasi orang dewasa di Amerika dan diprediksi 20\% dari populasi dunia menderita kecemasan (Kaplan \& Sadock, 2016).

Kecemasan adalah kekhawatiran yang tidak jelas dan menyebar, yang berkaitan dengan perasaan tidak pasti dan tidak berdaya. Keadaan emosi ini tidak memiliki objek yang spesifik. Kecemasan di alami secara subjektif dan dikomunikasikan secara interpersonal dapat menjadi suatu kekuatan motivasi untuk pertumbuhan dan perkembangan pada individu yang bersangkutan (Marbun, Pardede, 2019). Stres akan meningkatkan resistensi pembuluh darah perifer dan curah jantung sehingga akan menstimulasi aktivitas syaraf simpatik. Adapun stres ini dapat berhubungan dengan pekerjaan, kelas sosial, 
ekonomi, dan karakteristik personal (Setyaningsih, 2015). Salah satu cara yang dapat ditempuh penderita hipertensi adalah dengan menghindari stres dan cemas yang berlebihan serta beristirahat dengan cukup. Sebagai manusia terkadang tidak dapat terus menerus menjaga agar kondisi yang dianjurkan dokter dapat dipertahankan, sebab stres dan cemas sewaktu-waktu dapat menyerang penderita hipertensi (Zahara, 2017).

Hasil survey awal yang dilakukan di Jalan Amal Luhur 15 pada tanggal 5 Oktober 2021 kepada Ny. L didapatkan bahwa pasien menderita penyakit hipertensi dengan masalah psikososial kecemasan. Saat observasi diketahui pasien gelisah, wajah puca, tremor dan mengeluh badannya terasa lemas, kehilangan selera makan, dan saat dilakukan pengukuran tekanan darah Ny.L tinggi sehingga pasien tidak mampu melakukan aktivitas seperti biasanya.

\subsection{Tujuan}

\subsubsection{Tujuan Umum}

Berdasarkan latar belakang masalah tersebut maka dapat dirumuskan masalah sebagai berikut : Bagaimana Memberikan Asuhan Keperawatan Psikososial Pada Ny.L Dengan Masalah Kecemasan Di Jalan Amal Luhur Medan Helvetia

\subsubsection{Tujuan Khusus}

1. Mahasiswa mampu mengetahui defenisi, tanda \& gejala, faktor penyebab, mekanisme koping, penatalaksanaan pada pasien dengan Hipertensi Pada Psikososial Kecemasan Di Jalan Amal Luhur Medan Helvetia.

2. Mahasiswa mampu melakukan pengkajian pada pasien dengan Hipertensi Pada Psikososial Kecemasan Di Jalan Amal Luhur Medan Helvetia.

3. Mahasiswa mampu menegakkan diagnosa atau masalah keperawatan pada Ny.L dengan Hipertensi Pada Psikososial Kecemasan Di Jalan Amal Luhur Medan Helvetia. 
4. Mahasiswa mampu menetapkan intervensi keperawatan secara menyeluruh pada Ny.L dengan Hipertensi Pada Psikososial Kecemasan Di Jalan Amal Luhur Medan Helvetia.

5. Mahasiswa mampu melakukan tindakan keperawatan yang nyata pada Ny.L dengan Hipertensi Pada Psikososial Kecemasan Di Jalan Amal Luhur Medan Helvetia.

6. Mahasiswa mampu mengevaluasi sebagai tolak ukur guna menerapkan asuhan keperawatan pada Ny.L dengan Hipertensi Pada Psikososial Kecemasan Di Jalan Amal Luhur Medan Helvetia.

7. Mahasiswa mampu mendokumentasikan asuhan keperawatan pada Ny.L dengan Hipertensi Pada Psikososial Kecemasan Di Jalan Amal Luhur Medan Helvetia. 


\section{BAB 2}

\section{TINJAUAN TEORITIS}

\subsection{Konsep Kecemasan}

\subsubsection{Definisi}

Kecemasan (anxiety) merupakan perasaan takut yang tidak jelas penyebabnya dan tidak didukung oleh situasi yang ada. Kecemasan dapat dirasakan oleh setiap orang jika mengalami tekanan dan perasaan mendalam yang menyebabkan masalah psikiatrik dan dapat berkembang dalam jangka waktu lama. Kecemasan adalah kekhawatiran yang tidak jelas dan menyebar, yang berkaitan dengan perasaan tidak pasti dan tidak berdaya. Keadaan emosi ini tidak memiliki objek yang spesifik. Kecemasan di alami secara subjektif dan dikomunikasikan secara interpersonal dapat menjadi suatu kekuatan motivasi untuk pertumbuhan dan perkembangan pada individu yang bersangkutan (Marbun. Pardede \& Perkasa, 2019)

Kecemasan merupakan suatu respon psikologis maupun fisiologis individu terhadap suatu keadaan yang tidak menyenangkan, atau reaksi atas situasi yang dianggap mengancam. Kecemasan yang terjadi tidak saja dialami oleh seorang pasien tetapi dapat juga dialami oleh perawat karena perawat terkadang cemas ketika berhadapan dengan pasien dan keluarga pasien (Pardede, Keliat, Damanik \& Gulo, 2020)

\subsubsection{Etiologi}

Meski penyebab kecemasan belum sepenuhnya diketahui, namun gangguan keseimbangan neurotransmitter dalam otak dapat menimbulkan ansietas pada diri seseorang. Faktor genetik juga merupakan faktor yang dapat menimbulkan gangguan ini. Kecemasan terjadi ketika seseorang mengalami kesulitan menghadapi situasi, masalah dan tujuan hidup. Setiap individu menghadapi stres dengan cara yang berbeda-beda, seseorang dapat tumbuh dalam suatu situasi yang dapat menimbulkan stres berat 
pada orang lain. Adapun faktor-faktor yang mempengaruhi kecemasan (Setyaningsih, 2015) adalah :

\section{Faktor Predisposisi}

Stressor predisposisi adalah semua ketegangan dalam kehidupan yang dapat menyebabkan timbulnya kecemasan. Ketegangan dalam kehidupan tersebut dapat berupa :

a. Peristiwa Traumatik, yang dapat memicu terjadinya kecemasan berkaitan dengan krisis yang dialami individu baik krisis perkembangan atau situasional.

b. Konflik Emosional, yang dialami individu dan tidak terselesaikan dengan baik. Konflik antara id dan superego atau antara keinginan dan kenyataan dapat menimbulkan kecemasan pada individu.

c. Konsep diri terganggu akan menimbulkan ketidakmampuan individu berpikir secara realitas sehingga akan menimbulkan kecemasan.

d. Frustasi akan menimbulkan rasa ketidakberdayaan untuk mengambil keputusan yang berdampak terhadap ego.

e. Gangguan fisik akan menimbulkan kecemasan karena merupakan ancaman terhadap integritas fisik yang dapat mempengaruhi konsep diri individu.

f. Pola mekanisme koping keluarga atau pola keluarga menangani stress akan mempengaruhi individu dalam berespon terhadap konflik yang dialami karena pola mekanisme koping individu banyak dipelajari dalam keluarga.

g. Riwayat gangguan kecemasan dalam keluarga akan mempengaruhi respons individu dalam berespons terhadap konflik dan mengatasi kecemasannya.

h. Medikasi yang dapat memicu terjadinya kecemasan adalah pengobatan yang mengandung benzodiazepin, karena benzodiazepine dapat menekan neurotransmiter gamma amino butyric acid (GABA) yang mengontrol aktivitas neuron di otak yang bertanggung jawab menghasilkan kecemasan. 


\section{Faktor presipitasi}

Stresor presipitasi adalah semua ketegangan dalam kehidupan yang dapat mencetuskan timbulnya kecemasan (Setyaningsih, 2015). Stressor presipitasi kecemasan dikelompokkan menjadi dua bagian, yaitu

a. Ancaman terhadap integritas fisik. Ketegangan yang mengancam integritas fisik yang meliputi :

- Sumber Internal, meliputi kegagalan mekanisme fisiologis sistem imun, regulasi suhu tubuh, perubahan biologis normal (misalnya : hamil).

- Sumber Eksternal, meliputi paparan terhadap infeksi virus dan bakteri, polutan lingkungan, kecelakaan, kekurangan nutrisi, tidak adekuatnya tempat tinggal.

b. Ancaman terhadap harga diri meliputi sumber internal dan eksternal

- Sumber Internal : kesulitan dalam berhubungan interpersonal di rumah dan tempat kerja, penyesuaian terhadap peran baru. Berbagai ancaman terhadap integritas fisik juga dapat mengancam harga diri.

- Sumber Eksternal : kehilangan orang yang dicintai, perceraian, perubahan status pekerjaan, tekanan kelompok, sosial budaya.

\subsubsection{Tingkat Kecemasan}

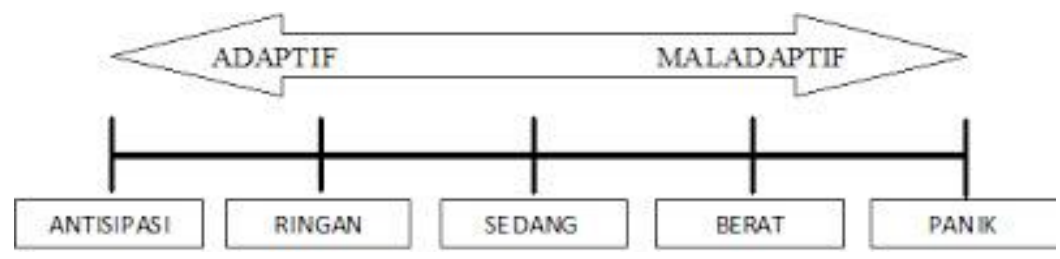

Rentang Respon Kecemasan (Stuart \& Sundeen, 1990).

1. Kecemasan ringan

Kecemasan ringan berhubungan dengan ketegangan akan peristiwa kehidupan sehari-hari. Pada tingkat ini lapangan persepsi melebar dan individu akan berhati-hati dan waspada. Individu terdorong untuk belajar yang akan menghasilkan pertumbuhan dan kreatifitas.

a. Respon Fisiologi: 
1) Sesekali napas pendek

2) Nadi dan tekanan darah naik

3) Gejala ringan pada lambung

4) Muka berkerut dan bibir bergetar

b. Respon Kognitif

1) Lapang persepsi melebar

2) Mampu menerima rangsangan yang kompleks

3) Konsentrasi pada masalah

4) Menjelaskan masalah secara efektif

c. Respon Perilaku dan Emosi:

1) Tidak dapat duduk tenang

2) Tremor halus pada tangan

3) Suara kadang-kadang meninggi

2. Kecemasan Sedang

Pada tingkat ini lapangan persepsi terhadap lingkungan menurun. Individu lebih memfokuskan hal-hal penting saat itu dan menyampingkan hal lain.

a. Respon Fisiologi:

1) Nadi (ekstra systole) dan tekanan darah naik

2) Mulut kering

3) Anorexia

4) Diare/konstipasi

5) Gelisah

b. Respon Kognitif:

1) Lapang persepsi menyempit

2) Rangsang luar tidak mampu diterima

3) Berfokus pada apa yang menjadi perhatian

c. Respon Perilaku dan Emosi:

1) Gerakan tersentak-sentak (meremas tangan)

2) Bicara banyak dan lebih cepat

3) Susah tidur

4) Perasaan tidak aman 


\section{Kecemasan Berat}

Pada kecemasan berat lapangan persepsi menjadi sangat sempit, individu cenderung memikirkan hal yang kecil saja dan mengabaikan hal lain. Individu tidak mampu lagi berpikir realistis dan membutuhkan banyak pengarahan untuk memusatkan perhatian pada area lain.

a. Respon Fisiologi:

1) Sering napas pendek

2) Nadi (ekstra systole) dan tekanan darah naik

3) Berkeringat dan sakit kepala

4) Penglihatan kabur

5) Ketegangan

b. Respon Kognitif:

1) Lapang persepsi sangat sempit

2) Tidak mampu menyelesaikan masalah

c. Respon Perilaku dan Emosi:

1) Perasaan ancaman meningkat

2) Verbalisasi cepat

3) Blocking

4. Panik

Pada tingkatan ini lapangan persepsi individu sudah sangat menyempit dan sudah terganggu sehingga tidak dapat mengendalikan diri lagi dan tidak dapat melakukan apa-apa walaupun telah di berikan pengarahan.

a. Respon Fisiologi

1) Sistem Kardiovaskuler
a) Palpitasi
b) Jantung berdebar
c) Tekanan darah meningkat
d) Denyut nadi menurun
e) Rasa mau pingsan

2) Sistem Respirasi 

a) Napas cepat
b) Pernapasan dangkal
c) Rasa tertekan pada dada
d) Pembengkakan pada tenggorokan
e) Rasa tercekik
f) Terengah-engah

3) Sistem Gastrointestinal
a) Kehilangan nafsu makan
b) Menolak makanan
c) Perasaan dangkal
d) Rasa tidak nyaman pada abdominal
e) Rasa terbakar pada jantung
f) Diare

4) Sistem Perkemihan
a) Inkontensia urine
b) Sering miksi

5) Sistem integument
a) Rasa terbakar
b) Berkeringat banyak di telapak tangan Gatal-gatal
c) Perasaan panas atau dingin pada kulit
d) Muka pucat
e) Berkeringat seluruh tubuh

b. Respon Kognitif

1) Gangguan perhatian

2) Konsentrasi hilang

3) Pelupa

4) Salah tafsir

5) Adanya bloking pada fikiran

6) Bingung

7) Rasa khawatir yang berlebihan

8) Kehilangan penilaian objektifitas

9) Takut akan kehilangan kembali 
10) Takut berlebihan

c. Respon Perilaku dan Emosi

1) Agitasi, mengamuk dan marah

2) Ketakutan, berteriak-teriak, blocking

3) Kehilangan kendali atau kontrol diri

4) Persepsi Kacau

d. Perilaku

1) Gelisah

2) Ketegangan fisik

3) Tremor

4) Gugup bicara cepat

5) Tidak ada koordinasi

6) Kecenderungan untuk celaka

7) Menarik diri

8) Menghindar

9) Terhambat melakukan aktifitas

\subsubsection{Penatalaksanaan}

Menurut Hawari (Yogiantoro, 2007) penatalaksanaan ansietas pada tahap pencegahaan dan terapi memerlukan suatu metode pendekatan yang bersifat holistik, yaitu mencangkup fisik (somatik), psikologik atau psikiatrik, psikososial dan psikoreligius. Selengkpanya seperti pada uraian berikut :

1. Upaya meningkatkan kekebalan terhadap stress, dengan cara :

a. Makan makanan yang berigizi dan seimbang

b. Tidur yang cukup

c. Olahraga yang teratur

d. Tidak merokok dan tidak minum minuman keras

2. Terapi Psikofarmaka

Terapi psikofarmaka yang sering dipakai adalah obat anti cemas (anxiolytic), yaitu seperti diazepam, clobazam, bromazepam, lorazepam, buspirone $\mathrm{HCl}$, meprobamate dan alprazolam. 
3. Terapi Somatik

Gejala atau keluhan fisik (somatik) sering dijumpai sebagai gejala ikutan atau akibat dari kecemasan yang bekerpanjangan. Untuk menghilangkan keluhan-keluhan somatik (fisik) itu dapat diberikan obat-obatan yang ditujukan pada organ tubuh yang bersangkutan.

4. Psikoterapi

Psikoterapi diberikan tergantung dari kebutuhan individu, antara lain
a. Psikoterapi Suportif
b. Psikoterapi Re-Edukatif
c. Psikoterapi Re-Konstruktif
d. Psikoterapi Kognitif
e. Psikoterapi Psikodinamik
f. Psikoterapi Keluarga

5. Terapi Psikoreligius

Untuk meningkatkan keimanan seseorang yang erat hubungannya dengan kekebalan dan daya tahan dalam menghadapi berbagai problem kehidupan yang merupakan stressor psikososial.

\subsection{Konsep Hipertensi}

\subsubsection{Definisi}

Hipertensi atau tekanan darah tinggi adalah suatu keadaan dimana tekanan darah sistolik $\geq 140 \mathrm{mmHg}$ dan atau tekanan darah diastolic $\geq$ $90 \mathrm{mmHg}$ (WHO, 2020). Hipertensi atau tekanan darah tinggi adalah suatu peningkatan abnormal tekanan darah daalam pembuluh darah arteri secara terus menerus lebih dari suatu periode. Hal ini terjadi bila arteriole-arteriole konstriksi. Kontriksi arteriole membuat darah sulit mengalir dan meningkatkan tekanan melawan dinding arteri. Hipertensi menambah beban kerja jantung dan arteri yang bila berlanjut dapat menimbulkan kerusakan jantung dan pembuluh darah (Setyawan \& Hasnah, 2020) 
Berdasarkan penyebabnya hipertensi terbagi menjadi dua golongan :

a. Hipertensi primer atau hipertensi esensial

Hipertensi primer atau hipertensi esensial disebut juga hipertensi idiopatik karena tidak diketahui penyebabnya. Faktor yang memengaruhi yaitu :

1) Genetik

Individu yang mempunyai riwayat keluarga dengan hipertensi, beresiko tinggi untuk mendapatkan penyakit ini. Faktor genetik ini tidak dapat dikendalikan, jika memiliki riwayat keluarga yang memliki tekanan darah tinggi.

2) Jenis kelamin dan usia

Laki - laki berusia 35- 50 tahun dan wanita menopause beresiko tinggi untuk mengalami hipertensi. Jika usia bertambah maka tekanan darah meningkat faktor ini tidak dapat dikendalikan serta jenis kelamin laki-laki lebih tinggi dari pada perempuan

3) Diet

Konsumsi diet tinggi garam secara langsung berhubungan dengan berkembangnya hipertensi. Faktor ini bisa dikendalikan oleh penderita dengan mengurangi konsumsinya, jika garam yang dikonsumsi berlebihan, ginjal yang bertugas untuk mengolah garam akan menahan cairan lebih banyak dari pada yang seharusnya didalam tubuh. Banyaknya cairan yang tertahan menyebabkan peningkatan pada volume darah. Beban ekstra yang dibawa oleh pembuluh darah inilah yang menyebabkan pembuluh darah bekerja ekstra yakni adanya peningkatan tekanan darah didalam dinding pembuluh darah dan menyebabkan tekanan darah meningkat.

4) Berat badan

Faktor ini dapat dikendalikan dimana bisa menjaga berat badan dalam keadaan normal atau ideal. Obesitas $(>25 \%$ 
diatas $\mathrm{BB}$ ideal) dikaitkan dengan berkembangnya peningkatan tekanan darah atau hipertensi.

5) Gaya hidup

Faktor ini dapat dikendalikan dengan pasien hidup dengan pola hidup sehat dengan menghindari faktor pemicu hipertensi yaitu merokok, dengan merokok berkaitan dengan jumlah rokok yang dihisap dalam waktu sehari dan dapat menghabiskan berapa putung rokok dan lama merokok berpengaruh dengan tekanan darah pasien. Konsumsi alkohol yang sering, atau berlebihan dan terus menerus dapat meningkatkan tekanan darah pasiensebaiknya jika memiliki tekanan darah tinggi pasien diminta untuk menghindari alkohol agar tekanan darah pasien dalam batas stabil dan pelihara gaya hidup sehat penting agar terhindar dari komplikasi yang bisa terjadi.

b. Hipertensi sekunder

Hipertensi sekunder terjadi akibat penyebab yang jelas.salah satu contohhipertensi sekunder adalah hipertensi vaskular rena, yang terjadiakibat stenosi arteri renalis. Kelainan ini dapat bersifat kongenital atau akibat aterosklerosis.stenosis arteri renalis menurunkan aliran darah ke ginjalsehingga terjadi pengaktifan baroreseptor ginjal, perangsangan pelepasn renin, dan pembentukan angiostenin II. Angiostenin II secara langsung meningkatkan tekanan darahdan secara tidak langsung meningkatkan sintesis andosteron danreabsorbsi natrium. Apabiladapat dilakukan perbaikan pada stenosis,atau apabila ginjal yang terkena diangkat,tekanan darah akan kembali ke normal.

\subsubsection{Patofisiologi}

Tekanan arteri sistemik adalah hasil dari perkalian cardiac output (curah jantung) dengan total tahanan prifer. Cardiac output (curah 
jantung) diperoleh dari perkalian antara stroke volume dengan heart rate (denyut jantug). Pengaturan tahanan perifer dipertahankan oleh sistem saraf otonom dan sirkulasi hormon. Empat sistem kontrol yang berperan dalam mempertahankan tekanan darah antara lain sistem baroreseptor arteri, pengaturan volume cairan tubuh, sistem renin angiotensin dan autoregulasi vaskular. Mekanisme yang mengontrol konstriksi dan relaksasi pembuluh darah terletak di vasomotor, pada medula diotak. Pusat vasomotor ini bermula pada saraf simpatis, yang berlanjut ke bawah korda spinalis dan keluar dari kolumna medulla spinalis ganglia simpatis di toraks dan abdomen. Rangsangan pusat vasomotor dihantarkan dalam bentuk implus yang bergerak kebawah melalui sistem saraf simpatis ke ganglia simpatis. Titik neuron preganglion melepaskan asetilkolin, yang akan merangsang serabut saraf paska ganglion ke pembuluh darah, dimana dengan dilepaskannya noreepineprin mengakibatkan konstriksi pembuluh darah.

Berbagai faktor seperti kecemasan dan ketakutan dapat mempengaruhi respon pembuluh darah terhadap rangsangan vasokontriksi. Individu dengan hipertensi sangat sensitif terhadap norepinefrin, meskipun tidak diketahui dengan jelas mengapa hal tersebut bisa terjadi .Meski etiologi hipertensi masih belum jelas, banyak faktor diduga memegang peranan dalam genesis hiepertensi seperti yang sudah dijelaskan dan faktor psikis, sistem saraf, ginjal, jantung pembuluh darah, kortikosteroid, katekolamin, angiotensin, sodium, dan air.

Sistem saraf simpatis merangsang pembuluh darah sebagai respon rangsang emosi, kelenjar adrenal juga terangsang, mengakibatkan tambahan aktivitas vasokontriksi. Medulla adrenal mensekresi epinefrin, yang menyebabkan vasokontriksi. Korteks adrenal mensekresi kortisol dan steroid lainnya, yang dapat memperkuat 
respon vasokonstriktor pembuluh darah. Vasokonstriksi yang mengakibatkan penurunan aliran keginjal, menyebabkan pelepasan rennin. Rennin merangsang pembentukan angiotensin I yang kemudian diubah menjadi angiotensin II, suatu vasokonstriktor kuat, yang pada gilirannya merangsang sekresi aldosteron oleh korteks adrenal. Hormon ini menyebabkan retensi natrium dan air oleh tubulus ginjal, menyebabkan peningkatan volume intra vaskuler.

\subsubsection{Manifestasi Klinis}

Tanda dan gejala utama hipertensi adalah menyebutkan gejala umum yang ditimbulkan akibat hipertensi atau tekanan darah tinggi tidak sama pada setiap orang, bahkan terkadang timbul tanpa tanda gejala. Secara umum gejala yang dikeluhkan oleh penderita hipertensi sebagai berikut:

1. Sakit kepala

2. Rasa pegal dan tidak nyaman pada tengkuk

3. Perasaan berputar seperti tujuh keliling serasa ingin jatuh

4. Berdebar atau detak jantung terasa cepat

5. Telinga berdenging yang memerlukan penanganan segera

\subsubsection{Komplikasi}

Tekanan darah tinggi bila tidak segera diobati atau ditanggulangi, dalam jangka panjang akan menyebabkan kerusakan ateri didalam tubuh sampai organ yang mendapat suplai darah dari arteri tersebut Komplikasi yang dapat terjadi pada penderita hipertensi yaitu :

a. Stroke terjadi akibat hemoragi disebabkan oleh tekanan darah tinggi di otak dan akibat embolus yang terlepas dari pembuluh selain otak yang terpajan tekanan darah tinggi.

b. Infark miokard dapat terjadi bila arteri koroner yang arterosklerotik tidak dapat menyuplai cukup oksigen ke miokardium dan apabila membentuk 12 trombus yang bisa memperlambat aliran darah melewati pembuluh darah. Hipertensi kronis dan hipertrofi ventrikel, kebutuhan oksigen miokardium 
tidak dapat dipenuhi dan dapat terjadi iskemia jantung yang menyebabkan infark. Sedangkan hipertrofi ventrikel dapat menyebabkan perubahan waktu hantaran listrik melintasi ventrikel terjadilah disritmia, hipoksia jantung, dan peningkatan resiko pembentukan bekuan.

c. Gagal jantung dapat disebabkan oleh peningkatan darah tinggi. Penderita hipertensi, beban kerja jantung akan meningkat, otot jantung akan mengendor dan berkurang elastisitasnya, disebut dekompensasi. Akibatnya jantung tidak mampu lagi memompa, banyak cairan tertahan diparu yang dapat menyebabkan sesak nafas (eudema) kondisi ini disebut gagal jantung.

d. Ginjal tekanan darah tinggi bisa menyebabkan kerusakan ginjal. Merusak sistem penyaringan dalam ginjal akibat ginjal tidak dapat membuat zat-zat yang tidak dibutuhkan tubuh yang masuk melalui aliran darah dan terjadi penumpukan dalam tubuh. 


\section{BAB 3}

\section{TINJAUAN KASUS}

\subsection{Pengkajian Keperawatan}

\begin{tabular}{|l|l|}
\hline Nama : Ny. L & Kondisi saat MRS: - \\
Usia : 62 tahun & Kondisi saat ini : \\
Tahun no reg :- & Ny. L mengeluh badannya terasa lemas, kehilangan selera makan, tekanan darah \\
Ruangan : - & tinggi sehingga Ny. L tidak mampu melakukan aktivitas seperti biasanya, \\
Tgl masuk rs: - & hingga membuat Ny. L merasa takut, gelisah dan tidak dapat melakukan \\
Tgl pengkajian : 1 Oktober & aktifitas seperti biasa. \\
2021 & \\
Alamat : Jalan Amal Luhur & \\
Medan Helvetia &
\end{tabular}

\section{Faktor Predisposisi Dan Faktor Presipitasi}

\begin{tabular}{|c|c|c|c|c|}
\hline \multirow[t]{2}{*}{ Faktor predisposisi } & \multicolumn{3}{|l|}{ Faktor presipitasi } & \multirow[t]{2}{*}{\begin{tabular}{|l} 
STRESSOR \\
\end{tabular}} \\
\hline & Nature & Origin & $\begin{array}{l}\text { Number } \quad \& \\
\text { Timing }\end{array}$ & \\
\hline $\begin{array}{l}\text { Biologis: } \\
\text { 1. Hipertensi } \\
\text { 2. Ny. L menderita gagal ginjal kronis tahun yang } \\
\text { lalu } \\
\text { 3. Ny. L sering mengkonsumsi makanan tinggi } \\
\text { garam } \\
\text { 4. Ny. L tidak rutin check up kepelayanan }\end{array}$ & 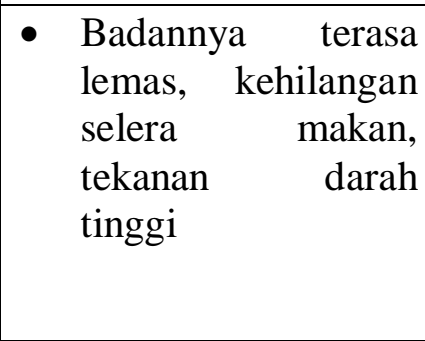 & Internal & $\begin{array}{lr}\text { Sejak } & 2 \\
\text { minggu } & \text { yang } \\
\text { lalu }\end{array}$ & - Hipertensi \\
\hline
\end{tabular}




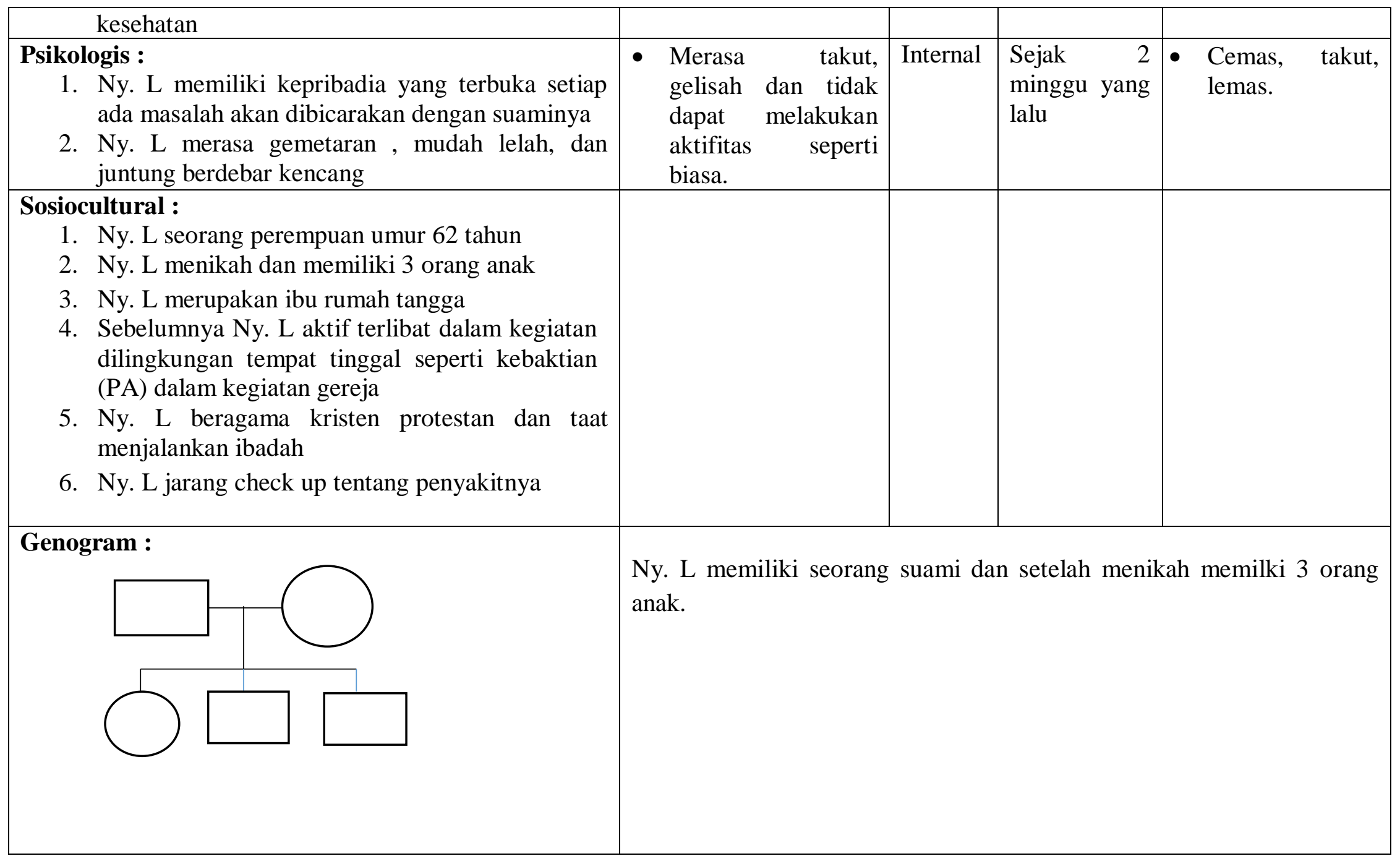




\begin{tabular}{|c|c|c|c|c|c|c|}
\hline STRESSOR & KOGNITIF & AFEKTIF & FISIOLOGIS & PERILAKU & SOSIAL & $\begin{array}{l}\text { DIAGNOSA } \\
\text { KEPERAWATAN }\end{array}$ \\
\hline \begin{tabular}{|l} 
BIOLOGIS \\
• Hipertensi
\end{tabular} & $\begin{array}{l}\text { - Menurut Ny. L } \\
\text { penyakit } \\
\text { Hipertensi } \\
\text { diakibatkan } \\
\text { karena } \\
\text { pengkonsumsi } \\
\text { makanan tinggi } \\
\text { garam } \\
\text { - Tidak tahu apa } \\
\text { yang harus } \\
\text { dilakukan untuk } \\
\text { penyakitnya } \\
\text { - Menganggap } \\
\text { penyakit yang } \\
\text { diderita serius }\end{array}$ & $\begin{array}{l}\text { - Ny. L } \\
\text { merasa sedih } \\
\text { dan juga } \\
\text { bingung } \\
\text { dengan } \\
\text { kondisi } \\
\text { penyakitnya } \\
\text { saat ini }\end{array}$ & $\begin{array}{l}\text { - } \text { Cemas } \\
\text { - Sulit tidur } \\
\text { - Tidak nafsu } \\
\text { makan } \\
\text { - Ny. T tampak } \\
\text { lemas } \\
\text { - Pemeriksaan } \\
\text { TTV } \\
\text { TD: } 145 / 90 \\
\text { mmHg } \\
\mathrm{N}: 88 \times \text { / menit } \\
\text { P : } 20 \mathrm{x} / \text { menit } \\
\text { S: } 37{ }^{0} \mathrm{C}\end{array}$ & \begin{tabular}{|l} 
- \\
jy. Lang \\
kontrol ke \\
rumah sakit \\
- Ekspresi \\
muka lesu \\
- Ny.T tampak \\
lemas dan \\
gemetaran
\end{tabular} & \begin{tabular}{|l} 
- Pasien \\
mendatangi \\
dan \\
menggunakan \\
fasilitas \\
kesehatan yang \\
ada untuk \\
mencari \\
kesembuhan \\
terhadap \\
masalah yang \\
dihadapi saat \\
ini
\end{tabular} & - Ansietas \\
\hline \begin{tabular}{|l} 
PSIKOLOGIS \\
- Sedih, cemas, \\
lemas dan \\
Kehilangan \\
selera makan
\end{tabular} & $\begin{array}{l}\text { - Ny. L tahu } \\
\text { bahwa } \\
\text { badannya terasa } \\
\text { lemas, } \\
\text { kehilangan } \\
\text { selera makan, }\end{array}$ & $\begin{array}{l}\text { - Merasa kesal } \\
\text { dengan } \\
\text { penyakitnya } \\
\text { yang tidak } \\
\text { sembuh- } \\
\text { sembuh }\end{array}$ & $\begin{array}{ll}\text { - } & \text { Sakit kepala } \\
\text { - } & \text { Sulit tidur dan } \\
\text { sering } \\
\text { terbangun } \\
\text { apabila tidur } \\
\text { - Tidak nafsu }\end{array}$ & $\begin{array}{l}\text { Tampak } \\
\text { cemas dan } \\
\text { tidak } \\
\text { tenang } \\
\text { - Kadang Ny. } \\
\text { L tampak }\end{array}$ & 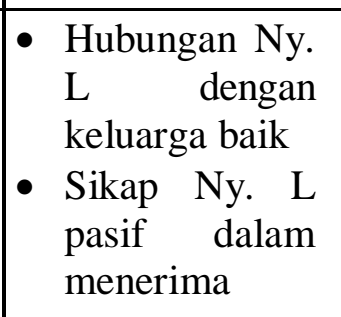 & - Ansietas \\
\hline
\end{tabular}




\begin{tabular}{|c|c|c|c|c|c|c|}
\hline $\begin{array}{l}\text { dengan kondisi } \\
\text { penyakit dan } \\
\text { pengobata } \\
\text { n serta } \\
\text { Perawatannya }\end{array}$ & $\begin{array}{l}\text { tekanan darah } \\
\text { tinggi sehingga } \\
\text { Ny. L tidak } \\
\text { mampu } \\
\text { melakukan } \\
\text { aktivitas seperti } \\
\text { biasanya, } \\
\text { hingga } \\
\text { membuat Ny. L } \\
\text { merasa takut, } \\
\text { gelisah dan } \\
\text { tidak dapat } \\
\text { melakukan } \\
\text { aktifitas seperti } \\
\text { biasa. }\end{array}$ & & $\begin{array}{l}\text { makan } \\
\text { - Ny. L tampak } \\
\text { lemas } \\
\text { - Wajah Ny. L } \\
\text { tampak lemas } \\
\text { - Pemeriksaan } \\
\text { TTV } \\
\text { TD: } 145 / 90 \\
\text { mmhg } \\
\mathrm{N}: 88 \times / \text { menit } \\
\mathrm{P}: 20 \mathrm{x} / \text { menit } \\
\text { S: } 37{ }^{0} \mathrm{C}\end{array}$ & $\begin{array}{l}\text { murung } \\
\text { - } \text { Ny.L } \\
\text { tampak } \\
\text { gelisah } \\
\text { - } \mathrm{Ny.} \quad \mathrm{L} \\
\text { tampak } \\
\text { pasif dalam } \\
\text { menerima } \\
\text { perawatan } \\
\text { Ny. } \\
\text { menunduk } \\
\text { saat bercerita }\end{array}$ & perawatan & Ketidakberdayaan \\
\hline $\begin{array}{l}\text { SOSIAL } \\
\text { BUDAYA } \\
\text { • Ny. L merasa } \\
\text { memikirkan } \\
\text { keluarga yang } \\
\text { masih yang harus } \\
\text { menjaga dan } \\
\text { merawatnya setiap } \\
\text { hari. }\end{array}$ & $\begin{array}{l}\text { - Ny. L merasa } \\
\text { harga dirinya } \\
\text { rendah } \\
\text { keadaannya } \\
\text { dengan keadaan } \\
\text { yang tidak bisa } \\
\text { bekerja bingung } \\
\text { memikirkan } \\
\text { anak-anak, } \\
\text { menurut pasien, } \\
\text { dukungan } \\
\text { keluarga nomor }\end{array}$ & $\begin{array}{l}\text { - Merasa } \\
\text { khawatir dan } \\
\text { sedih kepada } \\
\text { suami yang } \\
\text { merawatnya } \\
\text { setiap hari } \\
\text { - Merasa } \\
\text { bersalah } \\
\text { karena } \\
\text { merasa } \\
\text { merepotkan } \\
\text { suami }\end{array}$ & $\begin{array}{l}\text { - Pusing } \\
\text { - Mual } \\
\text { - Mulut tampak } \\
\text { kering } \\
\text { - Sulit tidur } \\
\text { - Tidak nafsu } \\
\text { makan } \\
\text { - Ny. L tampak } \\
\text { lemas } \\
\text { - Wajah Ny. L } \\
\text { tampak pucat } \\
\text { Pemeriksaan }\end{array}$ & $\begin{array}{ll}\text { Ny. } & \text { L } \\
\text { tampak } & \\
\text { gelisah } & \end{array}$ & $\begin{array}{l}\text { - Hubungan } \\
\text { Ny. L dengan } \\
\text { keluarga baik } \\
\text { - Hubungan } \\
\text { Ny. L dengan } \\
\text { petugas } \\
\text { kesehatan } \\
\text { baik } \\
\text { - Ny. L tetap } \\
\text { mengikuti } \\
\text { program } \\
\text { pengobatan }\end{array}$ & $\begin{array}{l}\text { Risiko Harga Diri } \\
\text { Rendah }\end{array}$ \\
\hline
\end{tabular}




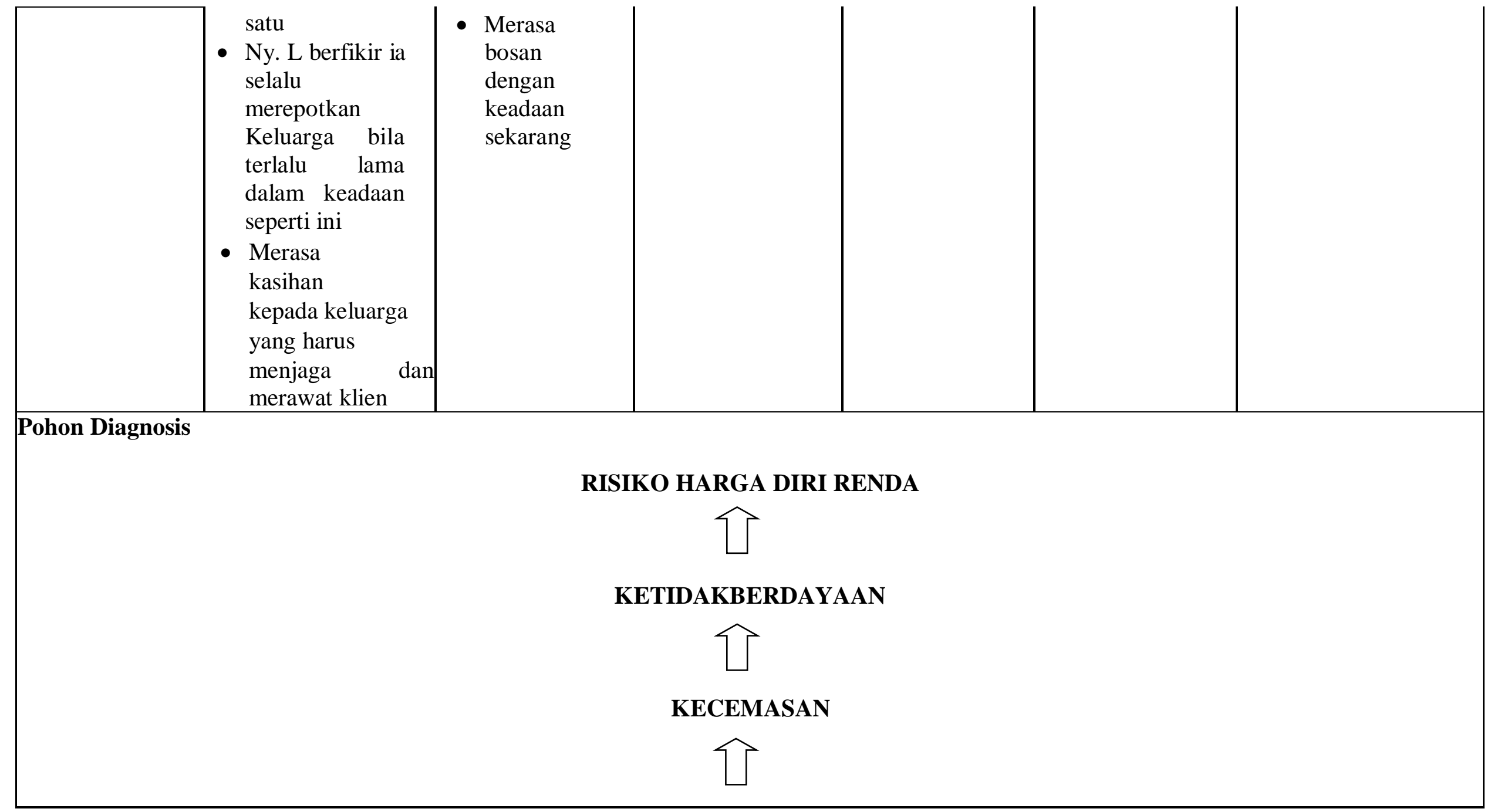




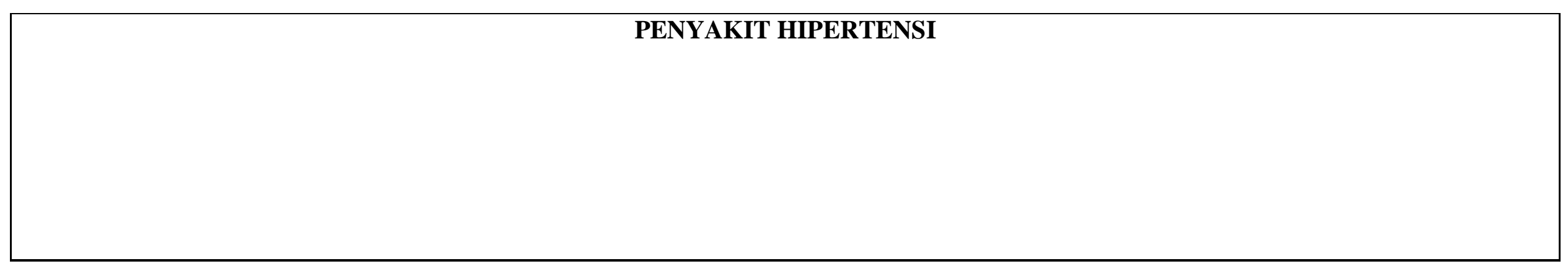




\section{SUMBER KOPING}

\begin{tabular}{|c|c|c|c|c|c|}
\hline $\begin{array}{c}\text { DIAGNOSA } \\
\text { KEPERAWATAN }\end{array}$ & PERSONAL ABILITY & $\begin{array}{c}\text { SOSIAL } \\
\text { SUPPORT }\end{array}$ & $\begin{array}{l}\text { MATERIAL } \\
\text { ASSETS }\end{array}$ & $\begin{array}{l}\text { POSITIE } \\
\text { BELIEFS }\end{array}$ & TERAPI \\
\hline Ansietas & $\begin{array}{l}\text { - Ny. L mampu } \\
\text { mengungkapkan } \\
\text { perasaan cemas } \\
\text { - Ny. L mengatakan bila } \\
\text { cemasnya memuncak } \\
\text { maka ia akan berdoa }\end{array}$ & $\begin{array}{l}\text { - Ny. L mendapat } \\
\text { dukungan dari } \\
\text { keluarga untuk } \\
\text { kesembuhannya } \\
\text { dan keluarga } \mathrm{Ny} \text {. } \\
\mathrm{L} \text { bergantian } \\
\text { merawat pasien }\end{array}$ & $\begin{array}{l}\text { - Sosial ekonomi } \\
\text { Ny. L menengah } \\
\text { dan pengobatan } \\
\text { ditanggung biaya } \\
\text { pribadi } \\
\text { - Jarak rumah Ny. } \\
\text { L dengan tempat } \\
\text { pelayanan } \\
\text { kesehatan lebih } \\
\text { kurang } 2 \mathrm{~km} \\
\end{array}$ & $\begin{array}{l}\text { - Ny. L percaya bahwa } \\
\text { petugas kesehatan } \\
\text { akan membantunya } \\
\text { - Ny. L berharap cepat } \\
\text { sembuh agar tidak } \\
\text { merepotkan } \\
\text { keluarga }\end{array}$ & 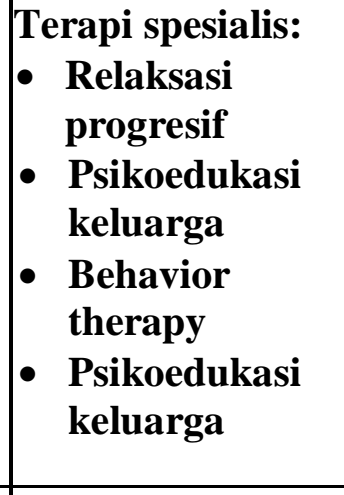 \\
\hline Kurang pengetahuan & $\begin{array}{l}\text { - Ny. L mampu } \\
\text { mengenal dan menilai } \\
\text { penyakitnya } \\
\text { - Ny. L mampu melatih } \\
\text { cara hidup sehat }\end{array}$ & $\begin{array}{l}\text { - Ny. L mendapat } \\
\text { dukungan dari } \\
\text { keluarga untuk } \\
\text { kesembuhannya } \\
\text { terutama dari } \\
\text { keluarga nya } \\
\text { - Keluarga Ny. L } \\
\text { bergantian } \\
\text { menjaga dan } \\
\text { mengunjungi } \\
\text { pasien }\end{array}$ & $\begin{array}{l}\text { - Sosial ekonomi } \\
\text { Ny. L menengah } \\
\text { - Ny. L tinggal di } \\
\text { rumah sendiri } \\
\text { - Sarana dan } \\
\text { prasarana } \\
\text { tersedia } \\
\text { - Biaya } \\
\text { pengobatan } \\
\text { ditanggung } \\
\text { keluarga } \\
\text { sendiri Ny.L } \\
\text { - Jarak rumah Ny } \\
\text { L dengan tempat }\end{array}$ & $\begin{array}{l}\text { - Ny. L percaya } \\
\text { bahwa petugas } \\
\text { kesehatan akan } \\
\text { membantunya } \\
\text { - Ny. L berharap } \\
\text { cepat sembuh agar } \\
\text { tidak merepotkan } \\
\text { keluarganya } \\
\text { - Ny. L selalu } \\
\text { berdoa untuk } \\
\text { kesembuhan } \\
\text { penyakitnya } \\
\text { Ny. L yakin, bila } \\
\text { ia mengikuti }\end{array}$ & $\begin{array}{l}\text { Terapi generalis: } \\
\text { - SP 1-2 kurang } \\
\text { pengetahuan } \\
\text { - } \text { Terapi } \\
\text { spesialis } \\
\text { - Terapi } \\
\text { suportif }\end{array}$ \\
\hline
\end{tabular}




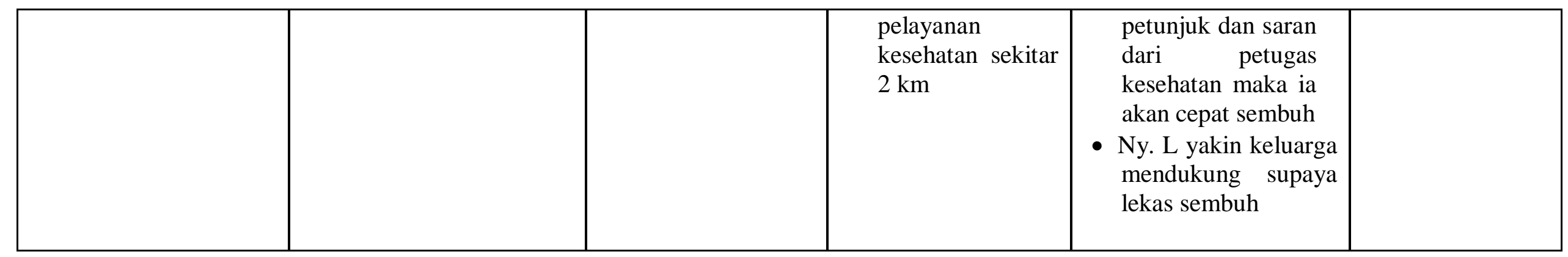




\section{MEKANISME KOPING}

\begin{tabular}{|c|c|}
\hline $\begin{array}{l}\text { HAL YANG } \\
\text { DILAKUKAN }\end{array}$ & ANALISA \\
\hline $\begin{array}{l}\text { - Ny. L mengatakan bila ada masalah, maka ia akan membicarakan } \\
\text { dengan suami dan keluarga untuk mencari jalan keluarnya } \\
\text { - Bila sakit Ny. L berobat ke pelayanan kesehatan } \\
\text { - Ny. L taat menjalankan ibadah sesuai dengan keyakinan yang ia } \\
\text { miliki } \\
\text { - Ny. L selalu berdoa kepada Tuhan untuk kesembuhannya }\end{array}$ & $\begin{array}{l}\text { - Konstruktif: } \\
\checkmark \text { Ny. L mengatakan bila ada masalah, maka ia akan } \\
\text { membicarakan dengan keluarga untuk mencari jalan } \\
\text { keluarnya } \\
\checkmark \text { Bila sakit Ny. L berobat ke pelayanan kesehatan } \\
\checkmark \text { Ny. L taat menjalankan ibadah sesuai } \\
\text { dengan keyakinannya } \\
\checkmark \text { Ny. L selalu berdoa kepada Tuhan untuk } \\
\text { kesembuhannya. } \\
\text { - Destruktif : - }\end{array}$ \\
\hline
\end{tabular}




\section{STATUS MENTAL}

\begin{tabular}{|l|l|}
\hline 1. Penampilan & Bersih, dan rapi \\
\hline 2. Pembicaraan & Ramah dan mau menceritakan semua hal yang dialami saat ini \\
\hline 3. Aktivitas motoric & Mampu berinteraksi \\
\hline 4. Interaksi selama wawancara & Ada kontak mata saat wawancara namun tidak tetap \\
\hline 5. Alam perasaan & Sedih, merasa cemas ,takut dan bingung mengenai penyakit yang dialami \\
\hline 6. Afek & Datar \\
\hline 7. Persepsi & Tidak ada gangguan persepsi dan sensori \\
\hline 8. Isi piker & Tidak ada gangguan isi pikir \\
\hline 9. Proses piker & Tidak ada ganggu proses pikir \\
\hline 10. Tingkat kesadaran & Normal \\
\hline 11. Daya ingat & Normal \\
\hline 12. Kemampuan berhitung & Tidak ada gangguan dalam berhitung \\
\hline 13. Penilaian & Ny. L mengambil keputusan saat merasa sakit dengan beribadah dan berdoa \\
\hline 14. Daya tilik diri & Ny. L menyadari memang merasa cemas \\
& \\
\hline
\end{tabular}




\section{DIAGNOSA DAN TERAPI}

\begin{tabular}{|l|l|}
\hline \multicolumn{1}{|c|}{ DIAGNOSA KEPERAWATAN DAN TERAPI } & DIAGNOSA MEDIS DAN TERAPI MEDIS \\
KEPERAWTAN & Hipertensi \\
\hline $\begin{array}{l}\text { 1. Ansietas } \\
\text { - Sp1: Mendiskusikan penyebab, terjadinya proses terjadi, } \\
\text { tanda dan gejala dan akibat }\end{array}$ & \\
- Sp2:Melatih teknik releksasi fisik & \\
- Sp3:Melatih mengatasi ansietas dengan distraksi dan & \\
- hipnotis lima jari & \\
2. Ketidakberdayaan mengatasi ansietas melalui kegiatan spiritual & \\
- Sp1. Assement ketidakerdayaan dan latihan berpikir positif & \\
- Sp2. Manfaat mengembangkan harapan positif dan latihan & \\
mengontrol perasaan & \\
3. Koping in efektif & \\
\end{tabular}




\section{IMPLEMENTASI TINDAKAN KPERAWATAN DAN EVALUASI}

\begin{tabular}{|l|l|}
\hline \multicolumn{1}{|c|}{ IMPLEMENTASI TINDAKAN KPERAWATAN } & \multicolumn{1}{c|}{ EVALUASI } \\
\hline Tanggal : 05 Oktober 2021 & $\begin{array}{l}\text { S: Pasien mengatakan : ansietasnya berkurang setalah } \\
\text { mengungkapkan perasaannya,pasien merasa tenang dan } \\
\text { Jam : } 10.00 \text {-14.00 wib }\end{array}$ \\
$\begin{array}{l}\text { 1. Menenangkan pasien } \\
\text { 2. Memahami keadaan pasien }\end{array}$ & $\begin{array}{l}\text { O : pasien tampak tenang setelah mengungkapakan } \\
\text { perasaan ansietasnya dan selalu melakukan tenik releksasi } \\
\text { 3. Mendiskusikan penyebab,terjadinya prosest terjadi, tanda gejala,akibat } \\
\text { 4. Mengkaji tingkat ansietas }\end{array}$ \\
$\begin{array}{l}\text { 5. Melatih pasien teknik relaksasi fisik tarik nafas dalam } \\
\text { 6. Melatih pasien mengatasi ansietas dengan ditraksi dan hipnotis lima jariansi dan hipnotis lima jari } \\
\text { 7. Mengkaji kegiatan spritual pasien } \\
\text { 8. Mendukung keterlibatan keluarga dengan cara yang tepat }\end{array}$ & $\begin{array}{l}\text { A: Ansietas pasien berkurang setalah melakukan teknik } \\
\text { releksasi tarik nafas dalam, ditraksi dan hipnotis lima jari }\end{array}$ \\
& P : intervensi dihentikan \\
\hline
\end{tabular}




\section{BAB 4}

\section{PEMBAHASAN}

Setelah penulis melaksanakan asuhan keperawatan kepada Ny. L dengan Kecemasan di Jalan Amal Luhur 15 maka penulis pada BAB ini akan membahasan kesenjangan antara teoritis dengan tinjauan kasus. Pembahasan dimulai melalui tahapan proses keperawatan yaitu pengkajian, diagnosa keperawatan, perencanaan, pelaksanaan dan evaluasi.

\subsection{Tahap Pengkajian}

Selama pengkajian dilakukan pengumpulan data dari beberapa sumber, yaitu dari pasien dan tetangga sekitar. Maka penulis melakukan pendekatan kepada pasien melalui komunikasi teraupetik yang lebih terbuka membantu klien untuk memecahkan perasaannya dan juga melakukan observasi kepada pasien. Adapun upaya tersebut yaitu :

a. Melakukan pendekatan dan membina hubungan saling percaya diri pada klien agar klien lebih terbuka dan lebih percaya dengan menggunakan perasaan.

b. Mengadakan pengkajian klien dengan wawancara dalam pengkajian ini, penulis tidak menemukan kesenjangan karena ditemukan hal sama seperti: diteori: Kecemasan adalah keadaan emosi dan pengalaman subyektif individu, tanpa objek yang spesifik karena ketidaktahuan dan mendahului pengalamanya yang baru seperti penyakitnya saat ini

\subsection{Tahap perencanaan}

Perencanaan dalam proses keperawatan lebih dikenal dengan rencana asuhan keperawatan yang merupakan tahap selanjutnya setelah pangkajian dan penentuan diagnosa keperawatan. Pada tahap perencanaan penulis hanya menyusun rencana tindakan keperawatan sesuai dengan pohon masalah keperawatan yaitu : Kecemasan. Pada tahap ini antara tinjauan teoritis dan tinjaun kasus tidak ada kesenjangan sehingga penulis dapat melaksanakan tindakan seoptimal mungkin dan didukung dengan seringnya bimbingan dengan pembimbing. Secara teoritis digunakan cara strategi 
pertemuan sesuai dengan diagnosa keperawatan yang muncul saat pengkajian. Adapun upaya yang dilakukan penulis yaitu :

1. Klien mengungkapkan ketidakpastian tentang fluktuasi tingkat energi dan bersikap pasif.

2. Klien menunjukan sikap apatis, depresi terhadap perburukan fisik yang terjadi dengan mengabaikan kepatuhan pasien terhadap program pengobatan

3. Klien mengalami ketergantungan pada orang lain yang dapat mengakibatkan ititabilitas, ketidaksukaan, marah dan rasa bersalah. Klien tidak melakukan praktik perawatan diri ketika ditantang. Klien tidak ikut memantau kemajuan pengobatan. Klien menunjukan ekspresi ketidakpuasan terhadap ketidakmampuan melakukan aktivitas atau tugas sebelumnya. Klien menunjukan ekspresi keraguan tantang performa peran.

\subsection{Tahap Implementasi}

Pada tahap implementasi, penulis hanya mengatasi 1 masalah keperawatan yakni: diagnosa keperawatan Kecemasan merupakan keadaan emosi dan pengalaman subyektif induvidu, tanpa objek spesifik karena ketidaktahuan dan mendahului semua pengalaman yang di alami penyakit Hipertensi

\subsection{Tahap Evaluasi}

Pada tinjauan teoritis evaluasi yang diharapkan adalah :

a. Membina hubungan saling percaya

b. Mengenali dan mengekspresikan emosinya

c. Mampu mengenal ansietas

d. Mampu mengatasi ansietas melalui teknik releksasi

e. Mampu mengatasi ansietas dengan distraksi

f. Mampu mengatasi ansietas melalui hipnotis lima jari 


\section{BAB 5}

\section{PENUTUP}

\subsection{Kesimpulan}

Berdasarkan uraian pada pembahasan diatas, maka penulis dapat disimpulkan bahwa:

1. Pengkajian dilakukan secara langsung pada klien dan juga dengan menjadikan status klien sebagai sumber informasi yang dapat mendukung data-data pengkajian. Selama proses pengkajian, perawat mengunakan komunikasi terapeutik serta membina hubungan saling percaya antara perawat-klien. Pada kasus Kecemasan : Hipertensi

2. Diagnosa keperawatan yang utama pada klien dengan Kecemasan: Hipertensi

3. Perencanaan dan implementasi keperawatan disesuaikan dengan strategi pertemuan pada pasien.

4. Evaluasi keperawatan yang dilakukan menggunakan metode subyektif,obyektif ,assessment dan planing.

\subsection{Saran}

1. Untuk institusi pendidikan

Diharapkan lebih meningkatkan pelayanan pendidikan yang lebih tinggi dan menghasilkan tenaga kesehatan yang profesional berwawasan global

2. Untuk keluarga

Diharapkan agar individu dan keluarga bisa mengerti tentang penyakit hipertensi, dan meningkatkan perilaku hidup sehat dengan tujuan meningkatkan kualitas hidup. 


\section{DAFTAR PUSTAKA}

1. Kaplan, MN., (2016). Kaplan's Clinical Hypertension. 9th ed. USA : Lippincott Williams \& Wilkins. Lancet ; 358 : 1682-1686.

2. Kemenkes RI, 2013. Pedoman Teknis Penemuan Dan Tatalaksana Hipertensi. Jakarta.

3. Marbun, A., Pardede, JA, \& Perkasa, SI (2019). Efektivitas Terapi Hipnotis Lima Jari terhadap Kecemasan Ibu Pre Partum di Klinik Chelsea Husada Tanjung Beringin Kabupaten Serdang Bedagai. Jurnal Keperawatan $\quad$ Prioritas , 2 (2), 92-99. https://doi.org/10.34012/jukep.v2i2.568

4. Pardede, J. A., Eli, D. S. P. H., \& Sirait, A. (2021). Tingkat Kecemasan Menurun Setelah Diberikan Terapi Hipnotis Lima Jari Pada Pasien Preoperatif. Jurnal Keperawatan, 13(1), 265-271. https://orcid.org/00000003-0114-4180

5. Pardede J.A \& Hulu E.K (2016) Dukungan Keluarga Dengan Tingkat Kecemasan Pasien Pre Operatif Di Rumah Sakit Sari Mutiara Medan. Jurnal Keperawatan Jiwa. 2(1).

6. Setyaningsih, R. D. (2015). Studi Prevalensi Dan Kajian Faktor Risiko Hipertensi Pada Lansia Di Desa Tambaksari - Banyumas. Prosiding Seminar Nasional \& Internasional, 1-6.

7. Setyawan, A., \& Hasnah, K. (2020). Efektivitas Wet Cupping Therapy Terhadap Kecemasan Pada Pasien Hipertensi. Jurnal Kesehatan Kusuma Husada, 212-217. https://doi.org/10.34035/jk.v11i2.574

8. Stuart, G. W. (2019). Buku saku keperawatan jiwa.

9. Triyanto,E. (2014). Pelayanan Keperawatan Bagi Penderita Hipertensi secara terpadu, Graha Ilmu. Jakarta.

10. Yogiantoro,E., (2007). Buku Ajar Ilmu Penyakit Dalam Jilid I. Departemen Ilmu Penyakit Dalam FK UI. Jakarta Pusat.

11. Zahara, F. (2019). Hubungan Antara Kecemasan Dengan Tekanan Darah Pada Penderita Hipertensi Di Rsu Pku Muhammadiyah Yogyakarta. Jurnal Psikologi Kognisi, 2(1), 42-53.. http://dx.doi.org/10.22303/kognisi.2.1.2017.42-53

12. Pardede, JA, Simanjuntak, GV, \& Waruwu, JFAP (2020). Penurunan Tingkat Kecemasan Pasien HIV/AIDS melalui Terapi Hipnotis Lima Jari. Mengatasi: Komunitas Penerbitan Keperawatan , 8, 85-90.

13. Pardede, JA, \& Tarigan, I. (2020). Tingkat Kecemasan Ibu Presectio Caesar dengan Terapi Relaksasi Benson. JURNAL KEPERAWATAN JENDELA (JNJ) , 4 (1), 20-28. https://doi.org/10.31983/jnj.v4i1.5801

14. Pardede, J. A., \& Simangunsong, M. M. (2020). Family Support With The Level of Preschool Children Anxiety in the Intravenous Installation. Jurnal Keperawatan Jiwa (JKJ): Persatuan Perawat Nasional Indonesia, 8(3), 223-234. https://doi.org/10.26714/jkj.8.3.2020.223-234 
15. Pardede, J. A., Keliat, B. A., Damanik, R. K., \& Gulo, A. R. B. (2020). Optimalization of Coping Nurses to Overcoming Anxiety in the Pandemic of Covid-19 in Era New Normal. Jurnal Peduli Masyarakat, 2(3), 105112. https://doi.org/10.37287/jpm.v2i3.128 